\title{
REALIDAD SOCIAL Y PROYECCIÓN CREADORA DE UNA CULTURA INSULAR: CUBA
}

\author{
ALEJANDRO GARCÍA ALVAREZ
}

E I enorme desarrollo que durante más de cinco siglos ha tenido la tecnología de los transportes terrestre, marítimo y aéreo, unido al paralelo desarrollo de las comunicaciones, han favorecido un complejo proceso de intercambios culturales que se resumen en el concepto de transculturación, tan utilizado por las Ciencias Sociales y Humanísticas en Cuba. ${ }^{1}$ Dicho proceso no solo ha facilitado la generalización de las culturas hegemónicas muchas veces amparado en acciones de conquista y de dominación neocolonial o clasista, sino que al mismo tiempo ha favorecido la traslación de personas, usos, costumbres y creencias desde los países dominados económica y políticamente hacia los centros dominadores o, simplemente, distanciados geográficamente.

Cuba constituye un caso en el cual la insularidad ha permitido una definida individualización dentro del ámbito caribeño, latinoamericano, en que está geográficamente insertada. Las primeras tres décadas del siglo $\mathrm{XX}$ sirvieron como un eficiente catalizador para el proceso de fortalecimiento de su identidad cul- tural, a partir de lo heredado de su propia historia, de su realidad social y de un fructífero intercambio con el exterior.

Variados han sido los factores que han propiciado la definición y el reconocimiento cultural de Cuba en el ámbito internacional. La estratégica isla caribeña ha sido, como también lo ha sido la totalidad de la América Latina, una receptora de valiosos componentes culturales importados desde otras latitudes, pero también ha formado parte de la corriente inversa que ha tenido lugar durante más de cinco siglos.

\section{EL COMPONENTE ARUACO}

Es conocido que la escasa y culturalmente rudimentaria población prehispánica del archipiélago cubano quedó prácticamente extinguida a causa del violento impacto de la conquista y el mestizaje. $\mathrm{Ni}$ en Cuba, ni en el resto de las Antillas quedan comunidades indígenas, tal y como existen en otros lugares del continente americano. Sin embargo, algunos elementos culturales de nuestra antigua población de origen 
aruaco han quedado fijados de manera permanente en nuestras islas e islotes $y$, al menos uno de ellos trascendió con descomunal fuerza hacia el exterior.

A pesar de los bautizos y fundaciones poblacionales realizados con el apoyo del santoral católico durante los siglos coloniales; a pesar de las implantaciones de nuevos nombres durante la República y, muy especialmente, a pesar de los cambios realizados en la toponimia a partir de los nombres de combatientes caídos en combate en época de la Revolución, la identificación de muchos de los principales lugares de Cuba descansa en una antigua terminología de origen aruaco, como también lo hacen la zoonimía y la fitonimía locales. ${ }^{2}$ En este sentido, Habana, Camagüey, Jatibonico, Bayamo, Baracoa, Guaniguanico, Hanábana, y cientos de otros nombres adornan con su sonoridad el territorio nacional. Plantas como el corojo, majagua, caoba, yagruma, son solo pequeños ejemplos. A nimales de especies distintas como el caimán, al miquí, macabí, guanabá o bibijagua, hoy mantienen inalterables sus nombres.

Pero el más trascendental componente de cubanía de procedencia aruaca ha sido enviado a todos los rincones del mundo desde el siglo XVII, como una especie de respuesta del dios de la Cohoba - Cohiba a la conquista y colonización de las islas. El portador material de dicha respuesta ha servido tradicionalmente para estimular el relajamiento de tensiones en la vida cotidiana y liberar el pensamiento creador en las personas; pero también ha podido afectar peligrosamente la salud de otros. Me refiero al tabaco y particularmente al producto manufacturado conocido como habano. Durante los siglos XVII y XVIII los habitantes de Cuba se dedicaron preferentemente al cultivo de esta hoja en los al rededores de las ciudades y en las márgenes de los ríos, contribuyendo al poblamiento europeo del campo cubano. Sin embargo, de la enorme difusión desu consumo en el día de hoy no somos enteramente responsables, así como tampoco sus principales beneficiarios.

\section{LA DEFINICIÓN DE COMPONENTES CULTURALESA PARTIR DEL AZÚCAR}

Durante la totalidad de los siglos XIX y $X X$, la sociedad y la cultura cubanas se desarrollaron bajo el influjo decisivo de la plantación azucarera que hasta 1886 había descansado en la explotación del trabajo esclavo. Unido al crecimiento de tal producción, se estabilizó la inmigración española y se potenció la inmigra ción forzada de africanos, los cuales incorporaron, además del color de su piel y su trabajo, sus creencias, costumbres, rituales y música de diversas procedencias. Lo yoruba, abakuá, arará y carabali, incorporaron sus respectivas culturas al tiempo que recibieron los aportes de la ya transculturadas costumbres y tradiciones de Cuba.

Sobre tan variada base social y cultural, la economía de la isla, dependiente de los mercados exteriores, había dado vida a un grupo de ciudades portuarias que sirvieron como centros receptores no sólo de las manufacturas extranjeras, sino también de viajeros y publicaciones comunicadoras de ideas, costumbres y creencias foráneas. A partir de las influencias recibidas y en unión creadora con la realidad interna, llegaron a conformarse los perfiles fundamentales de la sociedad y la cultura cubanas a lo largo de estos siglos. Dotada de una gran potencialidad vital, durante la etapa colonial la sociedad insular intentó en todo 
momento desarrollar sus propios intereses políticos y económicos paralelamente a los que la metrópolis española trató de hacer prevalecer por la fuerza de las decisiones burocráticas y el control militar. A causa de esta permanente contradicción, durante el siglo XIX y especialmente durante su segunda mitad, las ideas separatistas lograron ocupar un espacio importante en la conciencia nacional cubana como un componente esencial de la cultura política de la Nación.

La opción neocolonial instrumentada a partir de la intervención de los EE.UU. en la Guerra de Independencia colocó al país en el cauce de la vida republicana en 1902, sin haber alcanzado antes la plena autodeterminación nacional. Asignada a Cuba una función complementaria en la economía norteamericana como abastecedora de azúcar crudo, la plantación azucarera continuó extendiéndose por la isla durante los primeros veinticinco años del siglo XX, a la vez que la inmigración de braceros, entonces desde las cercanas Antillas, cobró nuevos bríos, al tiempo que se incrementaba la influencia de la nueva metrópolis a través de inversiones de capital, el dominio del mercado interior y la presión política sobre los asuntos internos de la recién creada República. Contradictoriamente, sobre estas frágiles bases se llevó a cabo la más completa maduración de un definido perfil cultural de carácter nacional. En el mismo se mezclaron los componentes sincréticos y mestizos propios del crisol étnico en que se había formado la nacionalidad cubana, con las ideas más diversas sobre la crítica situación de una sociedad que estaba padeciendo la dominación extranjera de un modo formalmente encubierto. Dicha realidad fue captada por la sensibilidad de pensadores, estudiosos y artistas, así como también por amplios sectores de la población. En la expresión cultural de los más esclarecidos exponentes de la nueva época, lo cubano afloró como una manifestación de lo propio y lo diferente; en otros casos surgió como crítica social consciente $y$, entre los más avanzados intelectuales y líderes, como aspiración a cambios que pudieran liberar a la sociedad cubana de las trabas impuestas por el neocolonialismo.

\section{CASI TODO SE HIZO A PARTIR DEL AZÚCAR}

Aunque Cuba arribó al siglo XX libre del dominio colonial español, ésta quedó subordinada a los intereses políticos y económicos de una nación más poderosa y cercana: los Estados Unidos de Norteamérica. A partir de entonces se operó un cambio en la intensidad y orientación del proceso histórico cubano cuyas características básicas fueron en términos generales: el acelerado ascenso de la producción azucarera, la dependencia de un mercado comprador y a la vez abastecedor fundamental, la penetración de capitales foráneos, y la dominación política de una nueva metrópolis diferenciada de la anterior, no solo en aquellos aspectos relacionados con el desarrollo económico y la orientación política, sino también en los órdenes cultural y social.

La Guerra de Independencia terminada en 1898 dejó un saldo negativo en la población de la isla. Ésta había sido afectada en casi 300000 almas, entre las muertes reportadas y la reducción de la tasa de natalidad en casi dos terceras partes. Las medidas represivas del mando militar español y el bloqueo naval norteamericano al finalizar la Guerra, no solo diezmaron la población sino que también la dislocaron, desarraigándola 
de sus lugares de asentamiento original. La población cubana en aquel momento estaba integrada por un $67,9 \%$ de blancos de origen español, un 32,1\% de negros y mestizos constituido por africanos y sus descendientes, a la vez que un $9 \%$ del total era reconocido como extranjero, principalmente españoles. ${ }^{3}$

También la agricultura cubana arribó al nuevo siglo con las afectaciones producidas por la Guerra. Una desigual distribución territorial y demográfica daba un peso económico superior a la región occidental con respecto a las antiguas provincias de Camagüey y Oriente. Un grupo de ciudades costeras entre las que se incluía la capital del país constituía el polo dominante de la economía y la política, a la vez que ejercía una suerte de liderazgo cultural; eran las ciudades del azúcar y el comercio. Otras poblaciones de singular importancia eran las capitales de provincia, que como Pinar del Río y Santa Clara, estaban enclavadas en zonas agrícolas vinculadas a las cosechas del tabaco y otros frutos, mientras que Camagüey representaba la entonces muy debilitada economía ganadera del País.

El transporte interior de la isla, desarrollado con el ferrocarril a partir de 1837 como un componente indispensable para la expansión azucarera del siglo $X I X$, lejos de haber servido a la unificación del mercado interno había logrado formar un conjunto de circuitos regionales vinculados a los puertos que comunicaban directamente con los mercados internacionales. Dicha realidad contribuyó a la diferenciación entre las regiones del Este y el Oeste de la isla, y a mantener su incomunicación por vía terrestre. El escaso intercambio entre ambas regiones se había realizado hasta entonces casi exclusivamente mediante la navegación de cabotaje.
Basado en diferentes premisas y compromisos mercantiles con EE.UU., la producción azucarera cubana resultó muy estimulada y logró crecer a un ritmo acelerado durante los primeros veinticinco años del siglo XX. Esto permitió en solo tres años la recuperaciòn de la principal industria hasta alcanzar los niveles anteriores a la Guerra, y la quintuplicación de dichos volúmenes en algo más de dos décadas, lo que significó una tasa media de crecimiento productivo de alrededor del $20 \%$ anual. Unido a la expansión azucarera, también los ferrocarriles de servicio público y privado crecieron y se extendieron hasta lograr la comunicación terrestre de todo el territorio nacional. Nuevos puertos y terminales marítimas se crearon y adaptaron a los requerimientos modernos y a los volúmenes mercantiles manipulados, especialmente en los casos de las provincias de Camagüey y de Oriente. Pero este inusitado crecimiento estuvo acompañado de profundas deformaciones. La más significativa de ellas fue la reconstitución del latifundio. Los antiguos corrales y hatos otorgados como mercedes de tierras por los cabildos cubanos desde el siglo XVI habían quedado demolidos casi en su totalidad al comenzar el siglo $X X$, aunque todavía permanecieron en forma de propiedades pro-indivisas unos pocos pero extensos fundos y también algunas tierras realengas, precisamente en aquellos lugares donde la plantación azucarera no había penetrado todavía.

El proceso expansivo de la principal industria trajo también modificaciones en la composición nacional de la población. El flujo migratorio de la antigua metrópolis se incrementó para incorporar posteriormente la importación de braceros de otros idiomas e idiosincrasia pro- 
cedentes de las diferentes islas de Las Antillas.

Aunque durante la primera década del siglo las necesidades de la agricultura cañera pudieron solventarse con macheteros y peones procedentes de la zona occidental de la isla, la posterior expansión de los cultivos cañeros hacia las provincias de Camagüey y Oriente demandó el concurso de fuerza laboral en cantidades superiores a la disponible en el país. Esta situación resultó favorable a la corriente inmigratoria que tanto desde España como desde Las Antillas se mantuvo vigente hasta después de $1925{ }^{4}$

\section{PAUTASMODERNIZADORASEN LA SOCIEDAD CUBANA.}

Como resultado de la expansión azucarera, las masas proletarias alcanzaron un gran incremento numérico y una superior madurez, tanto de orden organizativo como ideológico, especialmente durante y con posterioridad a la Primera Guerra Mundial y al surgimiento del primer estado socialista, y no obstante el peso de otros factores desfavorables, como lo fueron el fomento de la inmigración golondrina plurinacional y el incremento de distintas formas de represión clasista aplicadas por los sucesivos gobiernos republicanos.

Dicho proceso de desarrollo clasista fue el resultado directo de la extensión y profundización de las relaciones capitalistas en Cuba en el marco del sistema de dominación vigente. Como resultado de esto, y al igual que en el anterior siglo, los distintos sectores de la burguesía asentados en La Gran Antilla también estuvieron en condiciones de alcanzar nuevas etapas de su particular realización como clase y materializar algunas aspiraciones, especialmente las relacio- nadas con la ampliación del margen de beneficios económicos y sociales destinados a la satisfacción de sus requerimientos materiales y espirituales, y así lograr una calidad superior de vida basada en el privilegio social, equiparable al status de las burguesías europea y norteamericana de la época. Un ejemplo de ello lo constituye el patrimonio urbano de La Habana y otras ciudades del interior del país, y la existencia de valiosas colecciones de Arte Universal formadas mayoritariamente por la burguesía doméstica a lo extenso de casi dos siglos y que se encuentran actualmente en el Museo Nacional enclavado en la capital de Cuba.

En términos generales, las demandas de una población creciente estimularon tanto la actividad mercantil como la de los servicios, favoreciendo con ello la ampliación de las posibilidades de empleo entre las capas medias y sectores profesionales, e incrementando su influencia en el marco de la sociedad necolonial. Estos sectores no solo crecieron numéricamente, sino que su expresión culta fue capaz de reflejar con objetividad las inquietudes sociales, culturales y políticas del conjunto de la población.

A pesar de la bonanza económica, la desigualdad social contribuyó a que se produjera una polarización en los matices ideológicos de la sociedad cubana. En ella, tanto las profundas diferencias de clase como la dominación extranjera y la corrupción política, se perfilaron como una tríada de desgracias permanentes que asolaban continuamente al país. A ello se unió la venalidad de los gobernantes y la injerencia e intervención norteamericanas en los asuntos internos de Cuba. 5

El crecimiento de la producción y exportación de azúcar trajo aparejada la 
transformación del equipamiento agroindustrial y mercantil de la isla. La fundación y remodelación de los centrales azucareros se verificó a un ritmo vertiginoso bajo el signo de la electrificación. El proceso no significó en aquel momento la erradicación total del empleo del vapor, sino la incorporación de una fuerza motriz más moderna en los centrales. En un inicio, la planta eléctrica estuvo destinada a dar alumbrado y energía a algunos pasos del proceso industrial; posteriormente esto significó la electrificación total del proceso productivo.

Las normas de la vida rural fueron impuestas por la avasalladora acción de la industria azucarera. Comparado con el mísero remanso de paz que eran las zonas tabacaleras y de frutos menores, o con los niveles de vida primitivos que se imponían al campesinado marginado en las zonas de refugio de pantanos y montañas, la plantación cañera y los centrales podían considerarse como lugares esplendorosos y civilizados. Pero ¿qué tipo de civilización fue la impuesta por la explotación azucarera del gran central?. En las instalaciones agroindustriales creadas a partir del azúcar, la sociedad estaba rígidamente estratificada. Cada sector, cada capa social ocupaba no solo un lugar socialmente reconocido, sino también físicamente delimitado en la geografía de la gran plantación y su correspondiente centro urbano o batey. 6

En el batey azucarero el estado cubano no ejerció jurisdicción alguna hasta los años cuarenta del siglo XX. Una policía privada se encargaba del orden cotidiano. Sin embargo, la represión dasista en los momentos de agitación social debía quedar siempre a cargo del Ejército Nacional mediante la acción directa del cuerpo de caballería montada conocido como Guardia Rural. El pueblo azucarero agrupaba en su seno una fábrica de varios pisos, el complicado patio ferroviario y los sistemas de almacenaje, carga y descarga de la materia prima y el producto terminado. Otros tres elementos importantes completaban los servicios básicos de la instalación: la bodega o tienda mixta del ingenio, expresión del monopolio comercial ejercido por la empresa propietaria; la capilla, y también el club casi siempre de uso exclusivo. Próximo a las elevadas chimeneas del central se encontraba el suntuoso palacete de los propietarios. Así se comple taba un conjunto arquitectónico y tecnológico que haría parecer modestas las instalaciones del batey colonial y bucólica su actividad.

A la ampliación e instalación de nuevos ferrocarriles destinados tanto al uso público como al industrial, se unió la construcción de nuevos puertos exportadores, como A ntilla, en la bahía de N ipe, y Pastelillo y Puerto Tarafa en Nuevitas, además de un número indeterminado de puertos privados que operaban las empresas azucareras. Nuevas poblaciones como Florida, M orón, Ciego de A vila y Jatibonico surgieron o crecieron rápidamente como resultado de la expansión del azúcar y los transportes ferroviarios, mientras que los viejos puertos coloniales eran dragados e incrementaban sus capacidades de almacenaje y atraque ${ }^{7}$

La modernización que tuvo lugar con impresionante celeridad en la industria azucarera, también alcanzó, aunque con cierto retraso, las zonas urbanas. Varias ciudades fueron dotadas de equipamiento e infraestructura adecuada, tales como los servicios de alumbrado eléctrico público en sustitución del gas, la construcción de alcantarillado y acue ductos, a todo lo cual se unió el servicio de los tranvías eléctricos. Sin embargo, la 
mayoría de las poblaciones más importantes de la isla continuaron mostrando parecida imagen a la que habían ofrecido en los tiempos coloniales. En este sentido, La Habana sí pudo exhibir algunas innovaciones de relevancia que trocaron su aspecto un tanto provinciano en el de una gran urbe cosmopolita. En ella el desarrollo urbano se materializó sobre todo a partir de los años de la Primera Guerra Mundial, cuando se destruyeron los últimos grandes tramos de la muralla que había encerrado el recinto histórico de la ciudad, y que concluiría durante la década de los veinte y los críticos años iniciales de la de los treinta. De aquellos tiempos data la modernización de las avenidas y parques capitalinos; se rellenaron varias zonas del litoral, y se pavimentaron las calles de La Habana como una respuesta al inusitado incremento del tráfico automotor. Al tranvía eléctrico siguió la importación masiva de automóviles y camiones que, procedentes de la industria automotriz norteamericana, comenzaron a inundar las calles, sobre todo en la capital de la República. Pero la más significativa noción del progreso material se hizo patente mediante la extensión de los límites de la capital hacia el vecino municipio de $M$ arianao, antiguo lugar de estancias y de veraneo. En él se fomentaron nuevos barrios residenciales con suntuosas edificaciones y también se parcelaron otras zonas para la construcción de casas destinadas a obre ros sobre la base de planes oficiales. En este último caso se trató generalmente de planes destinados a la revalorización de terrenos mediante la urbanización de espacios periféricos.

Tanto en La Habana como en las urbes provinciales fueron edificados palacetes destinados al alojamiento de clubes y sociedades de recreo de la mayor exclusividad. A partir de estas instituciones se fueron asimilando los nuevos patrones que regirían la actividad recreativa y las costumbres de las clases acomodadas, haciéndolas transitar desde las formas aristocráticas de inspiración europea que habían prevalecido entre los miembros de la burguesía de origen hispano, hasta la adopción de normas de conducta de apariencia más democráticas, pero ferozmente exclusivistas, que habían sido asimiladas por el contacto cada vez más intenso con la sociedad norteamericana de la época.

La capacidad adquisitiva de los sectores acomodados de la sociedad cubana permitió la difusión de los patrones representativos de la cultura universal, especialmente entre dichos sectores y las capas medias de la población, a partir del consumo y disfrute, no solo de artículos y bienes materiales de la industria extranjera, sino también de un producto cultural muy acabado que regularmente provenía de Europa o EE.UU.. La oferta del producto cultural quedó generalmente garantizada por las compañías europeas de teatro y ópera, concertistas de fama, así como por las empresas cinematográficas tanto europeas como norteamericanas. Los grandes artistas de la época y también los de mayor popularidad, pasaron por los escenarios cubanos dejando su estimulante ejemplo de profesionalismo como contribución para el desarrollo del arte nacional. 8

\section{UN GRAN SALTO EN LA EXPRESIÓN CULTURAL}

La realidad nacional en que Cuba se debatía durante las tres primeras décadas del siglo XX fue el resultado de un proceso activado por la acción conjunta del gobierno de los EE.UU., las empresas 
monopolistas norteamericanas y sus inevitables aliados nacionales. Dicha realidad fue captada y reflejada por la expresión culta del país, llegándose a conformar una imagen objetiva de la misma en la obra de los creadores. Fue precisamente a partir de la década del veinte, cuando un sector representativo del capital doméstico, el conocido como burguesía hispano-cubana, vio frustradas sus aspiraciones de lograr una influencia determinante sobre la economía y la política nacionales. En aquel momento se hizo más que evidente el sometimiento abierto o disimulado de las administraciones cubanas a los intereses de los EE.UU., como casi única garantía para la estabilidad de las mismas, cuestión que era reconocida por la generalidad del pueblo como una deleznable experiencia a la cual quedaron unidos la injerencia en los asuntos internos del país y la intervención, como prácticas políticas habituales de los gobiernos norteamericanos con relación a Cuba.

Fue precisamente a partir del agravamiento de las condiciones propias de la realidad cubana, definidas en términos de dominación extranjera, injusticia social, corrupción y empleo reiterado de la represión, cuando comenzaron a manifestarse con mayor fuerza, superior grado de madurez y coherencia, tanto el pensamiento sociológico como la obra de los artistas e intelectuales más destacados de Cuba en la primera mitad del siglo $X X$. Los esfuerzos por retomar el pensamiento cubano más esclarecido del anterior siglo fueron seguidos de un propósito consciente por dar continuidad al mismo y adaptarlo a las circunstancias específicas de cada momento. A la tendencia adoptada con frecuencia por intel ectuales y artistas desde los inicios del siglo XIX, en cuanto a estimular la incor- poración de las modernas corrientes universales de pensamiento y sus formas de expresión en el ámbito de la creación artística como un rechazo a los esquemas y valores heredados de la colonia, le siguieron los más variados esfuerzos por lograr la identificación de los componentes culturales de "lo cubano", y su integración creadora con el objetivo de lograr el establecimiento e interpretación de las más genuinas raíces de la identidad nacional. 9

En los primeros años de la República, los componentes básicos de la cubanía; es decir, lo español y lo africano, habían sido valorados por separado. Reforzada por una inmigración masiva de peninsulares, la influencia española quedó apuntalada por el poder económico de que habían dispuesto los ciudadanos de la Madre Patria desde el siglo anterior, y también por sus propias instituciones, órganos de prensa, el clero católico y una parte importante de los centros educacionales privados. Estos factores permitieron el mantenimiento de los valores y formas de la cultura ibérica con singular vigencia, mientras que se intensificaba el ya tradicional intercambio con otros valores y formas surgidos o asimilados a partir de la experiencia sociocultural cubana.

El componente africano de la cultura nacional había sido visto hasta entonces por los sectores medios y burgueses de la sociedad como un cuerpo extraño. Al origen esclavo, la religiosidad y costumbres diferenciadas, se añadieron como elementos negativos el color de la piel $y$, sobre todo, la carencia de poder económico. Todo ello colocó a la pobla ción negra de Cuba en aquellos años, bajo el signo de la discriminación. Tanto las creencias religiosas como los hábitos alimentarios, costumbres, música y otras 
manifestaciones propias del etnos afrocubano, fueron usualmente considerados bajo la simple denominación de cosa de negros, y algunas de sus prácticas colocadas en el plano de la marginalidad rayanas con el delito. Por ello no resulta extraño que en 1912 algunos grupos de la población negra optaran por iniciar la lucha por sus derechos civiles mediante su incorporación a un movimiento armado que se conocería como M ovimiento de los Independientes de Color. A la represión más feroz siguió la prohibición por más de 25 años de todas aquellas manifestaciones públicas de la población negra, tales como procesiones religiosas, comparsas, celebración del carnaval y otras. Como en la Edad Media europea, las acusaciones de brujería y los procesos escandalosos contra los negros se encargaron de completar el cuadro de descrédito reservado a la población negra, al terminar la segunda década del siglo $\mathrm{XX} .10$

La búsqueda y defensa de una expresión cultural propia haciendo abstracción de los componentes hispano y africano había conducido desde el siglo XIX a no pocos intelectuales y artistas a optar por la identificación de lo genuinamente cubano en las raíces indígenas, en lo aruaco, al modo que lo había realizado en aquel siglo el poeta Juan Cristóbal Nápoles Fajardo, conocido como El Cucalambé. Otros habían optado por la vía del rechazo más absoluto a la cultura de origen hispano y africano heredada de la época colonial, para plantearse la asimilación de otros patrones culturales europeos. También existió la tendencia de fundir los componentes de la cultura occidental más universal con la tradición criolla del siglo $\mathrm{XIX}$, tal y como en alguna medida lo lograra el músico Eduardo Sánchez de Fuentes. Sin embargo, en las más repre- sentativas expresiones de la plástica, la música y la literatura de las décadas de los veinte y treinta, quedaron finalmente expresados con toda su riqueza los componentes de una cultura heredada y decantada, que hundía sus dispersas raíces tanto en el pasado como en el presente mismo.

Formados en la Universidad de la Habana, la A cademia de Bellas Artes de San Alejandro, o en las distintas academias, conservatorios e instituciones públicas y privadas de la isla, los creadores cubanos de las tres primeras décadas del siglo XX dispusieron de una base docente de cierta consideración para su formación profesional. Herederos de una tradición de cubanía alimentada secularmente por los componentes hispanos y africanos, e influenciados por las características contemporáneas de los habitats urbano y rural de la isla, los intelectuales y artistas nacionales de aquella época recibieron también el aliento que la vida cultural europea y americana habían continuado irradiando hacia La Mayor de Las Antillas. Cuba, encrucijada de viajeros, fue un espacio abierto a la influencia de personalidades y corrientes que descollaban en el arte y la política de cada época.

Mediante el contacto creador con el extranjero, el estudio sistemático, o las vivencias adquiridas por la permanencia en los grandes centros culturales líderes, los creadores que animaron la vida cultural en aquellas decisivas décadas iniciales del siglo XX, recibieron por distintas vías la savia de las nuevas concepciones e ideas del cómo reflejar, interpretar y transformar la realidad en que se vivía. Dicha época resultó decisiva para la maduración de la cultura cubana contemporánea. Ella dejó como saldo un irrepetible pero coherente conjunto de 
realizaciones que estableció las pautas fundamentales para el posterior de sarrollo de una expresión propia de lo nacional cubano, y lo dejó plasmado mediante un lenguaje a tono con los tiempos en que se vivía.

\section{EL REFLEJO DE LA VIDA SOCIAL EN LOS CREADORES}

Desde el momento mismo en que se inició la Primera Intervención norteamericana en la isla, el verso romántico de los poetas de la primera generación republicana, como el de Bonifacio Byrne, se trocó en vehículo de exaltación patriótica; al mismo tiempo, la reanudación de la línea modernista se erigió como negación crítica de los valores coloniales en poetas como Regino Boti y José $M$. Poveda. Transida de cubanía, la poesía de Agustín Acosta se convirtió en portadora de la angustia, inconformidad y pesimismo ante una realidad aparentemente imposible de ser transformada a favor de las ansias de justicia social y autodeterminación del pueblo cubano.11

Fue precisamente la crítica al estado de cosas prevaleciente, el centro alrededor del cual giraron algunas otras manifestaciones de la cultura nacional en los primeros años de la República. De manera similar al ensayo de crítica social y política, la novelística del primer cuarto de siglo republicano proporcionó un testimonio de gran realismo que reflejó las crudas realidades de la época. Las novelas del periodista Jesús Castellanos, así como las del dirigente obrero y más tarde académico Carlos Loveira; las del médico Miguel de Carrión, unidas a lo escrito por el sociólogo José Antonio Ramos, aportaron al conocimiento de la re alidad contemporánea mucho más que el discurso apologético o la oposición de magógica de los políticos en sus discursos y declaraciones dirigidas a una clientela electoral ansiosa de cambios.

El ritmo de las publicaciones, diarios y revistas se incrementó considerable mente. De este período data la fundación (1916) de una revista frívola en su origen, que devino en trascendente vehículo de divulgación cultural. La revista Social tuvo mucho que ver con el modo de vida burgués, pero sirvió a la vez para dar a conocer los valores de la cultura tanto nacional como universal. Otras publica ciones como la revista Cuba Contemporánea (1913) dieron cabida a los análisis y opiniones de las más diversas tendencias sobre los problemas contemporáneos, con un superior nivel de especialización.

Casi al terminar la década de los veinte surgió la Revista de A vance (1927). Muy influenciada por la española Revista de Occidente, este órgano de difusión cultural insistió durante su corta existencia de tres años, en la actualización del pensamiento cubano y las ideas sobre la renovación estética. Vocero de un pensamiento de vanguardia, dicha publicación marcó un momento excepcional en la historia de la cultura cubana caracterizado por la sobrevaloración de la capacidad de los intelectuales para dar solución a los problemas del país mediante el esfuerzo de una minoría de hombres y mujeres cultos. ${ }^{12}$ Con el cese de esta publicación en 1930 quedó enterrada una visión idealista del progreso social. Posteriormente dicha visión quedó superada por una realidad en que se impuso la lucha de masas contra la tiranía ejercida por el general Gerardo Machado y el sistema de dominación neocolonial prevaleciente en el país. 
No obstante el auge experimentado en los medios de difusión cultural, las profundas diferencias existentes en la sociedad cubana, unido al nivel de analfabetismo prevaleciente entre las masas de trabajadores y campesinos, así como la incomunicación de numerosas zonas rurales, motivaron el que amplios sectores de la sociedad se mantuvieran todavía privados del acceso, no solo a la cultura, sino también a la educación escolar. Según el censo de 1931, solo el 36,5 de la población de entre 5 y 9 años de edad podía asistir regularmente a la escuela. ${ }^{13}$

$\mathrm{Si}$ bien es cierto que durante el segundo gobierno republicano (1909-1913) se trató de institucionalizar la actividad de los intelectuales mediante la creación de entidades oficiales como la Academia Nacional de Artes y Letras y la Academia de la Historia, al tiempo que iniciaba su precaria existencia el Museo Nacional,14 la década de los veinte contempló la proliferación de instituciones privadas, agrupaciones y órganos de difusión independientes, surgidos como resultado de un movimiento espontáneo de intelectuales y artistas que habían alcanzado un grado superior de madurez y conciencia nacional. En este sentido cabe mencionar la Sociedad del Folklore Cubano (1923) y la Institución HispanoCubana de Cultura (1926), fomentadas bajo la dirección del destacado sociólogo e historiador Fernando Ortiz. Sin embargo, la manifestación suprema de la labor de los intelectuales y artistas de la década de los veinte se concretó en un movimiento carente de organicidad institucional, pero rebosante de dinamismo y participación en la vida cultural y política del país. Surgido a partir de un combativo núcleo de escritores que había protagonizado una protesta política en el ámbito cultural en el año de 1923, el 'Grupo Minorista' planteó una actitud nueva por parte de los artistas e intelectuales que expresaba abiertamente su inconformidad con las lacras republicanas y, en especial, con respecto a la corrupción administrativa del gobierno del presidente Alfredo Zayas. En su quehacer quedaron plasmados al unísono el amor a la cultura y la acción revolucionaria. Su programa introdujo una toma de posiciones con respecto a la crisis de la sociedad cubana al mismo tiempo que arremetió contra los falsos valores culturales, para finalmente orientarse hacia la búsqueda de nuevas perspectivas para la creación. Los 'minoristas' se manifestaron contra el alejamiento de los intelectuales de la vida política nacional, abogando por que los mismos asumieran posturas más comprometidas con el porvenir de la Patria. ${ }^{15}$

\section{LO CUBANO EN LAS MANIFESTACIONESARTÍSTICAS.}

Los más destacados pintores formados en la etapa colonial, Leopoldo Romañach y Armando G. Menocal, asumieron desde el inicio de la República una búsqueda de lo cubano mediante vías distintas; el primero mediante el paisaje y la escena centrada en la figura humana, generalmente expresiva de cierto dramatismo social. En Menocal el tema épico de la Guerra de Independencia, de la cual fue protagonista, estuvo presente especialmente en su obra por encargo oficial. En ambos casos se trata de los puntales de la pintura cubana de las dos primeras décadas del siglo que a la vez fueron portadores de un quehacer académico de gran oficio, el cual, sin embargo, no rebasó las formas del impresionismo de fines del siglo XIX.16 
Influenciada por las mismas circunstancias sociales y culturales que accionaron sobre el conjunto de la creación intelectual, la pintura modificó sustancialmente su orientación en la década de los veinte, sobre la base de lograr el apresamiento del tema cubano y el empleo de una expresión fundamentada en las corrientes y técnicas de vanguardia que entonces se abrían paso en Europa y América. Cubismo, expresionismo, sustentadores de temas urbanos y rurales, pero basados en tipos y personajes cubanos, comenzaron a enriquecer la plástica nacional mediante la paleta y el dibujo elegante de Víctor Manuel García, - la transparencia escurridiza de Carlos Enríquez. El hecho cotidiano como tema fue ayudado por el fino dibujo de Arístides Fernández, mientras que el cubismo de Amelia Peláez entraba en los patios interiores coloniales para recibir una nueva dimensión plástica. Todos ellos dieron un original sentido a la pintura cubana de los años veinte, de finiendo su orientación futura. Los pintores cubanos contemporáneos son continuadores directos de la obra renovada que comenzó a manifestarse en la década de los veinte; en ello radica su actual coherencia como movimiento pictórico.

Pero fue en la música donde más temprana y espontáneamente se integraron y expresaron con mayor fuerza los componentes de lo español y lo africano. Quizás el hecho de que tradicionalmente los músicos hubieran provenido del sector 'de color' de la sociedad cubana haya favorecido la libre interpretación de los cánones musicales europeos, mediante versiones en las que el ritmo, la sensualidad y los instrumentos de percusión pasaron a desempeñar un papel fundamental para la expresión musical. Es pre- cisamente la música el componente mayor y quizás el más divulgado de la expresión cultural de lo cubano. Un ejemplo de ello es el surgimiento del danzón en 1877, a partir de la contradanza ampliamente cultivada en el siglo XIX, para convertirse durante la República en un baile de aceptación nacional entre todas las clases sociales. No sería hasta los años 20 en que, procedente de la provincia más oriental se introdujo en el occidente de Cuba la canción bailable conocida popularmente como Son; el cual hasta fechas todavía muy cercanas ha gozado de gran popularidad en todo el país y también en el extranjero. ${ }^{17}$ Es en esta misma dirección que se han proyectado internacionalmente fórmulas musicales cubanas, antiguas y marineras, como lo es el caso de la habanera, y la guajira, actualmente muy aceptada, espe cialmente en la muy divulgada Guantanamera. Sones, guarachas, mambos y la salsa, ya no son solo patrimonio de Cuba sino del ancho mundo en que vivimos.

Una más compleja vertiente de la creación musical tuvo como base el teatro. Proveniente de una tradición vernácula muy fuerte existente en la escena cubana, el teatro musical mantuvo su vigencia en los primeros treinta años del siglo, a partir del teatro 'Alhambra', burlesco habanero en el que se combinaban la picardía con la crítica política y la música. Sin embargo, no fue sino hasta finales de la década del veinte y principios de la del treinta cuando el género logró rebasar el ámbito del teatro 'solo para hombres', con la incorporación de jóvenes valores musical es que resultarían insignes como Ernesto Lecuona, Gonzalo Roig $y$, posteriormente Rodrigo Prats, quienes le hicieron sal ir de aquel estrecho marco de espectadores exclusivamente masculinos. El sainete de crítica costum- 
brista y política resultó así superado por obras de mayor pretensión que retomaba la zarzuela española a partir de temas, personajes y música propiamente cubanos. Con el estreno de 'Niña Rita' en 1927, Ernesto Lecuona marcó un hito en el teatro lírico cubano ${ }^{18}$, estrenándose posteriormente obras de teatro musical muy emblemáticas como lo son $\mathrm{M}$ aría la 0 , Cecilia Valdés, o El Cafetal. Así, en la trama de estas obras, la mulata de rumbo se convirtió en el personaje más relevante del teatro musical dela isla.

Con la inauguración de la República el 20 de mayo de 1902, la música había entrado de nuevo en los cauces de una divulgación popular, mediante la actuación de bandas de concierto que fueron creadas bajo el patrocinio de los regimientos militares y los ayuntamientos municipales. La urbana tradición coIonial de la "retreta"se recuperó para convertirse en un medio idóneo para la difusión de la música escrita por los grandes autores universalmente reconocidos, entre la población de las ciudades y los pueblos. En el caso de La Habana, esta labor la desempeñaron músicos de gran arraigo y talento, como Guillermo Tomás y Gonzalo Roig. Dicha actividad contribuyó al cultivo de la sensibilidad musical entre las capas populares. También entre los sectores élites de la capital se materializó plenamente el interés por la divulgación de esta elevada manifestación artística. Con la fundación de la Sociedad Pro-Arte Musical en 1916, quedó establecida una premisa importante para el posterior desarrollo de la música de concierto en Cuba.

Dirigidas al propósito de difundir la música sinfónica se crearon en la década del 20 dos importantes instituciones orquestales en La Habana. En 1922, por iniciativa de Gonzalo Roig y con el apoyo del eminente cellista ibérico Pablo Casals, se creó la Orquesta Sinfónica Nacional. Dos años más tarde, la exclusiva Sociedad Pro-Arte Musical contrató al músico español Pedro Sanjuán para fundar la Orquesta Filarmónica de La Habana. Esta emulación redundó en beneficio de la música en Cuba, al introducirse una orientación moderna y ser divulgados músicos contemporáneos poco conocidos en la isla, como Manuel de Falla, Maurice Ravel y Claudio Debussy. La introducción de elementos de modernidad en la música también re sultó estimulante para franquear el acceso y la asimilación de los tambores y ritmos afrocubanos por parte del ámbito musical sinfónico, que pasaron a ser considerados como una expresión representativa de la música sinfónica cubana.

Las nuevas concepciones musicales se manifestaron sobre todo mediante la obra de creadores como Amadeo Roldán y A lejandro García Caturla, quienes marcaron el inicio del moderno arte sinfónico cubano. Con la "Obertura sobre temas cubanos", estrenada en 1925, fijó Roldán una fecha capital en la música cubana, mientras que el talento y diversidad formal comenzaba a manifestarse en $\mathrm{Ca}$ turla, con Tres danzas cubanas y Rumba (1927), Canto guajiro (1928), y D os poemas sinfónicos y Bembé (1929).19

\section{UNAS BREVESIDEASCOMO CONCLUSIÓN}

El rechazo simultáneo de la herencia coIonial y de las manifestaciones de africanía mantuvieron a la expresión culta de los artistas e intelectuales cubanos privada de formas y contenidos esenciales casi hasta la década de los treinta, con la excepción casi exclusiva de la música popular. Sin embargo, durante la se- 
gunda década del siglo, ya se habían comprobado los efectos negativos que la dominación imperialista causaba al país. Fue a partir de entonces que se abrió paso con fuerza una reacción entre los diversos sectores de la población, que tendía al rescate y defensa de los intere ses y valores propios de la Nación, al mismo tiempo que se ponía énfasis en de la falta de perspectivas para dar solución práctica a los problemas fundamentales de la realidad cubana dentro de los límites del sistema de dominación impuesto al país. Problemas como el latifundismo y la inmigración incontrolada fueron sometidos al juicio crítico de destacados intelectuales, mientras que el dominio norteamericano sobre la economía de la isla, la discriminación y la penetración cultural, generaban evaluaciones negativas por parte de dirigentes de casi todos los sectores nacionales. La reflexión crítica sobre dicho estado de cosas hizo que finalmente surgiera en el seno de la sociedad cubana una corriente antimperialista de considerables proporciones.

Junto a su pueblo, los creadores formados en la República comenzaron a expresar sus ideas de rechazo a la realidad en que habían vivido, utilizando para ello, tanto el ensayo de crítica económica, social y política, como el lenguaje de la poesía y la literatura de ficción basada en un gran realismo social. En esferas más independientes y distantes de la realidad social, como frecuentemente son consideradas la música y las artes plásticas, también dicha realidad tuvo un reflejo apropiado. Lo cubano comenzó a ser expresado con autenticidad, maestría y sentido crítico, dejando sentadas las bases para la creación futura.

Al iniciarse la década de los treinta, la opción neocolonial norteamericana impuesta a Cuba había quedado mode lada en su totalidad, pero al mismo tiempo también se habían identificado y registrado los síntomas de crisis de un sistema de dominación, considerablemente agravado por la situación que atravesaba el capitalismo mundial desde 1929. Ya para entonces aparecieron planteados como cuestiones fundamentales, tanto la búsqueda de los valores más legítimos de la cultura nacional como la identificación de sus vínculos con las expresiones más universales de lo contemporáneo. La crítica y el rechazo a la opción neocolonial fueron los síntomas inequívocos del grado de conciencia que habían alcanzado los creadores y artistas cubanos ante una trágica realidad que reclamaba con urgencia su transformación.

Tanto por la madurez y representatividad de la obra realizada, como por la participación en la vida social mediante las agrupaciones y órganos de difusión formados por los mismos, los intelectuales y artistas de los primeros treinta años de vida republicana crearon las condiciones necesarias para dotar a las generaciones sucesivas de los más valiosos elementos de la tradición nacional y a la vez comunicarles sus alientos modernizadores. El desarrollo alcanzado por la cultura cubana hasta nuestros días tiene una especial deuda con las generaciones de artistas e intel ectuales que, durante las décadas de los veinte y treinta del siglo $\mathrm{XX}$, dieron un significativo impulso para la formación del valioso patrimonio cultural que recibiera la Revolución en enero de 1959, y el cual de algún modo ha llevado consigo la fuerte emigración que desde la decada de los sesenta ha tenido lugar a partir de La Mayor de las Antillas. 


\section{ENDNOTES}

1 Se trata de un concepto novedoso introducido por el notable sociólogo e historiador cubano Don Fernando Ortiz, para establecer la idea de una acción recíproca en el intercambio de las culturas, superando así la idea del flujo unidireccional atribuído a los procesos de dominación cultural.

2 Ver M apa G eotopográfico de Cuba de Esteban Pichardo (1859) y A tlas $\mathrm{N}$ acional de Cuba, (1970); además el D iccionario Geográfico, H istórico y Estadístico de la Isla de Cuba de Jacobo de la Pezuela, y Cuba en la M ano, obra encidopedia sobre Cuba ( $\mathrm{La}$ Habana: 1940).

3 Informe sobre el Censo de Cuba, 1899, (Washington: Imprenta del Gobierno, 1900) pp. 44-45 y 481-484.

4 J. Pérez de la Riva, 'Cuba y la migración antillana 1899-1931', en La República Neocolonial, t. 2. (La Habana: Editorial de Ciencias Sociales, 1979, tabla VIII-I) y 'LoS Recursos Humanos al Comenzar el Siglo', en La república N eocolonial, t. 1, 1973, p. 44; ver tambien A bel Losada en Cuba, Población y Economía Entre la Independencia y la Revolución, (Universidad de Vigo: Servicio de Publicaciones, 1999) pp. 94102.

5 En este sentido pueden mencionarse la Segunda Intervención norteamericana entre 1906 y 1909 y el desembarco de marines en 1912 y 1917. A ello se agregan la injerencia de un delegado especial del presidente norteamericano en Cuba, entre 1919 y 1923, y la llamada 'mediación' de año 1933.

6 Batey es el término aborígen utilizado en Cuba para designar un pequeño caserío, aunque se aplica generalmente al conjunto de instalaciones, viviendas y espacios que rodean una fábrica de azúcar o central. Instituto de Historia de Cuba, La
N eocolonia. Reoganización y Crisis, ( La Habana: Editora Política, 1998) pp. 136138, y A. García Alvarez, De la Consolidación a la Crisis, (La Habana: Editorial Félix Varela, 2001) pp. 85-86y 98-105.

7 A. García Alvarez, La Gran Burguesía Comercial en Cuba, 1899-1920. (La Habana: Editorial de Ciencias sociales, 1990, pp. 48-56).

8 A. García Alvarez, D écadas D efinitorias de la Sociedad y la Cultura en Cuba. 1900-1940, (Revista A rbor: Madrid, julio-agosto de 1991) pp. 204-205.

9 A. García Alvarez, Décadas D efinitorias pp. 206-207; E. Carpentier, La M úsica en Cuba, (La Habana: Editorial Letras Cubanas, 1979) p. 220.

10 Para el particular problema de los derechos de la población negra y su lucha, ver: A. Helg, 0 ur Rightful Share. The A fro.Cuban Struggle for Equality, 1886-1912. (Chapel Hill: The University of North Carolina Press, 1995). Un caso particular de acusaciones de brujería a los negros está contenido en la obra de E. Chávez Alvarez, El crimen de la Niña Cecilia, (La Habana: Editorial de Ciencias Sociales, 1991).

11 J. A. Portuondo, Bosquejo H istórico de las Letras Cubana, (La Habana: 1973) p. 46; J. Ibarra Cuesta, N ación y Cultura N acional, (La Habana: Editorial Letras Cubanas, 1981) p. 45.

12 Portuondo, Bosquejo H istórico, y A. A ugier, Prosa V aria, (La Habana: Editorial de Letras Cubanas, 1982) pp. 170-171.

13 M emorias inéditas del censo de 1931, (La Habana: Editorial de Ciencias Sociales 1978) tabla 19, p. 252.

14 En La Habana existía desde la segunda mitad del siglo XIX un museo de Ciencias auspiciado por la Academia de Ciencias Físicas y Matemáticas. Entre 1899 y 1900 
se habían creado mediante el patrocinio privado, los museos 'Emilio Bacardí ' de Santiago de Cuba y el 'Oscar M. de Rojas' de Cárdenas.

15 A. Carpentier, Conferencia,. (La Habana: Editorial Letras Cubanas, 1987) p. 140; E. Roig de Leuchsenring, El Grupo M inorista de Intelectuales y A rtistas $\mathrm{H}$ abanero, ( $\mathrm{La}$ Habana: Oficina del Historiador de la Ciudad, 1961, p. 17); A. Cairo, El Grupo M inorista y su Tiempo, ( La Habana: Editorial de Ciencias Sociales, 1979, pp. 49-50).

16 E. Valderrama, La Pintura y la Escultura en Cuba, La Habana: Editorial Lex, 1952, pp. 5-15 y 71-76).

17 A. García Alvarez, D écadas D efinitorias, pp. 210-211: A. Carpentier, La M úsica,.pp. 122 y 188; H. Orovio, D iccionario de la M úsica Cubana, (La Habana Editorial Letras Cubanas, 1981) p. 379.

18 E. Robreño, Como Lo Pienso lo Digo, (La Habana: Editorial Unión, 1985) p. 172.

$19 \mathrm{H}$. Orovio, Diccionario de la M úsica Cubana, pp. 162 y 351; A. García Alvarez, D écadas Definitorias, pp. 211-213, y Cuba en la mano. Enciclopedia Popular Ilustrada, (La Habana: Ucar, García y Cía) pp. 1004. 